\title{
On the Very Idea of Brandom's Pragmatism
}

\author{
Tadeusz Szubka
}

Received: 4 February 2010 /Revised: 12 July 2010 / Accepted: 15 October 2010 /

Published online: 10 November 2010

C The Author(s) 2010. This article is published with open access at Springerlink.com

\begin{abstract}
Although Brandom is critical of some features of narrowly conceived classical pragmatism, at the same time he explicitly embraces a version of pragmatism, both in his overall philosophical outlook, and in his philosophy of language. Brandom's distinctive theoretical approach is based on what he calls rationalist pragmatism, which is a version of fundamental pragmatism. Within the philosophy of language it takes the form of semantic pragmatism. The paper briefly discusses Brandomian version of fundamental pragmatism and its semantic underpinning, and subsequently formulates a basic dilemma it encounters there.
\end{abstract}

Keywords Neo-pragmatism · Rationalist pragmatism $\cdot$ Fundamental pragmatism · Semantic pragmatism $\cdot$ Meaning $\cdot$ Use $\cdot$ Use specification $\cdot$ Normativity $\cdot$ Pragmatic expressive bootstrapping

Neo-pragmatism or New Pragmatism is certainly a very distinctive movement in recent philosophy. There are several outstanding philosophers associated with it, including Hilary Putnam and Richard Rorty. ${ }^{1}$ Among them there is also Robert B. Brandom, one of the leading American philosophers of his generation. Although he

\footnotetext{
${ }^{1}$ It is a rather contentious issue what is the best term to describe this movement and which philosophers should be included in it. For instance, in the introduction to an interesting collection of essays by various authors on New Pragmatism, Cheryl Misak (2007) is prepared to follow the suggestion of Ian Hacking and confine the label "Neo-pragmatism" for a radical and subjective version of pragmatism defended by Rorty, while reserving the term "New Pragmatists" for these recent thinkers who are making every effort to carry on the pragmatic tradition in the moderate and objective spirit. Alan Malachowski (2010) is more inclusive in his use of the expression "the New Pragmatism", and thinks it fits well both Rorty and Putnam. However, he would like to see the disappearance of the term "Neo-pragmatism", since according to him the prefix "neo" "almost always carries connotations of substandardness, as if the version in question is not quite the real thing" (Malachowski 2010, p. x). My suggestion is to put these misleading terminological idiosyncrasies and seeming connotations aside, and use "the New Pragmatism" and "Neo-pragmatism" as generally interchangeable terms.
}

T. Szubka $(\bowtie)$

Philosophy Institute, Szczecin University, Krakowska 71-79, PL 71-017 Szczecin, Poland

e-mail: szubka@univ.szczecin.pl 
is critical of some features of narrowly conceived classical pragmatism, at the same time he explicitly embraces a version of pragmatism, both in his overall philosophical outlook, and in the philosophy of language. His distinctive theoretical approach is based on what he calls rationalist pragmatism, which is a version of fundamental pragmatism. Within the philosophy of language it takes the form of semantic pragmatism. The paper briefly discusses Brandomian version of fundamental pragmatism and its semantic underpinning, and subsequently formulates a basic dilemma it encounters there. The gist of the discussion will be as follows: fundamental pragmatism is either a vague programmatic idea without specific content, or involves highly contentious claims requiring adequate support. Brandom wants to support it by semantic pragmatism. This view, however, is itself either trivial, or questionable.

\section{Fundamental and Rationalist Pragmatism}

Brandom's pragmatism has explicit affinities both with global pragmatism conceived as a distinctive approach to philosophical questions, and with local pragmatism within the philosophy of language.

To put it very roughly, the distinctive trait of the former is to take human practice as a crucial factor in our theorizing, that is as providing evidence for our theories and constraining them in various ways. Brandom described the former

as a movement centered on the primacy of the practical, initiated already by Kant, whose twentieth-century avatars include not only Peirce, James and Dewey, but also the early Heidegger, the later Wittgenstein, and such figures as Quine, Sellars, Davidson and Rorty (Brandom 2002a, p. 40).

This is certainly a broad construal of pragmatism, since it is not confined to what is known as classical American pragmatism, and its more or less faithful contemporary followers. ${ }^{2}$ Of course, there will be as many varieties of pragmatism in this broad and inclusive sense, as there are ways of conceiving "the primacy of the practical", and especially the domain of practice and the practical. For Brandom, even if not, apparently, for many mainstream or classical pragmatists, ${ }^{3}$ at the center of human practice are characteristically rational activities of seeking and providing reasons. To put it in currently popular jargon, the practical domain is the space of

\footnotetext{
${ }^{2}$ A similarly broad construal of pragmatism has been also proposed by Charles Taylor. He includes in it Heidegger, Merleau-Ponty, Wittgenstein, as well as the great American figures of the last turn of the century who embraced the designation (Taylor 2004, p. 75). For Taylor pragmatism is an approach to philosophical questions that insists on the primacy of practical reasons, on "pragmata" over merely neutral states of affairs. Although extensionally equivalent to Brandom's broad account of pragmatism, it is presumably different in various details of emphasis. Brandom hints at these differences in his comment on Taylor's paper (Brandom 2010a, pp. 301-304).

${ }^{3}$ Brandom (2002a, 2004, 2010b) has various misgivings about several ideas often taken as constitutive of classical pragmatism. It is arguable to what extent he is right in his criticisms, and to what extent his criticisms are heavily dependent, as Putnam (2002) insists, upon misconstruing classical pragmatism. For an assessment of the disagreement between Brandom and Putnam in this matter see Baghramian (2008).
} 
reasons. This enables Brandom to claim that his pragmatism is uniquely rationalist one. As he himself explains:

It is a rationalist pragmatism, in giving pride of place to practices of giving and asking for reasons, understanding them as conferring conceptual content on performances, expressions, and states suitably caught up in those practices (Brandom 2000, p. 11).

The elements of such a rationalist pragmatism can even be discerned in the work of Hegel, although this is prima facie surprising. According to Brandom Hegel is a pragmatist in virtue of "his commitment to understanding determinately contentful empirical conceptual norms as instituted by experience, the process of using those concepts by applying them in practice: making judgments and performing actions" (Brandom 2002b, pp. 56 and 233).

For Brandom such a rationalist pragmatism is a tenable version of fundamental pragmatism, that is a general view assigning explanatory priority to knowing how over knowing that. One can also put it in terms of understanding, and say that according to a fundamental pragmatist propositional explicit knowledge should be understood in terms of what one does, in terms of a set of practical abilities. Briefly, for the view in question "explicit theoretical beliefs can be made intelligible only against a background of implicit practical abilities" (Brandom 2002a, p. 46). At first sight this is a plausible position to take, but troubles begin when an attempt is made to specify practical abilities and doings which are supposed to ground and explain theoretical beliefs and knowledge. Given a variety of philosophical positions held by thinkers included by Brandom among global pragmatists, it is reasonable to assume that no distinctive way of specifying practical abilities and doings will be preferred here. Perhaps anything which is performed by us will count as a doing or action, and it won't be necessary to describe it in some selected vocabulary (e.g. in physical, biological, behavioral, or functional one) in order to invoke it in understanding or explanation of propositional contentful beliefs and knowledge. However, by allowing advocates of global pragmatism such a latitude in this matter, one puts their view at risk of being easily trivialized, since it will suffice to propose an explanation of any phenomenon in terms of processes producing it (e.g. beliefs in terms of believings, representations in terms of representings, wishes in terms of wishings) to be included among pragmatists in this sense. It seems that inclusiveness is achieved here at the cost of making requirements of being a pragmatist very insubstantial indeed.

Brandom might reply to this charge as follows. It is true that fundamental pragmatism is in itself a very broad and unspecific position without any substantial philosophical commitments. ${ }^{4}$ However, one should remember that his version of fundamental pragmatism is a rationalist one, and this means that there is a class of doings which are unique and deserve special attention. What really matters in the case of humans is what we do with language when we are engaged in the social game of asking for and giving reasons. Here how Brandom elaborates it:

The game of giving and asking for reasons is not just one game among others one can play with language. It is the game in virtue of the playing of which

\footnotetext{
${ }^{4}$ In his introduction to $2010 \mathrm{~b}$ Brandom makes it clear that "fundamental pragmatism" is a relatively loose and elastic description which may be variously interpreted as to fit the methodology of many thinkers.
} 
what one has qualifies as language (or thought) at all. I am here disagreeing with Wittgenstein, when he claims that language has no downtown. On my view, it does, and that downtown (the region around which all the rest of discourse is arrayed as dependent suburbs) is the practices of giving and asking for reasons. This is a kind of linguistic rationalism. 'Rationalism' in this sense does not entail intellectualism, the doctrine that every implicit mastery of a propriety of practice is ultimately to be explained by appeal to a prior explicit grasp of a principle. It is entirely compatible with the sort of pragmatism that sees things the other way around (Brandom 2009, p. 120).

This linguistic and rationalist pragmatism is combined with the commitment to the idea that human practices of giving and asking for reasons are significantly dissimilar from, and discontinuous with, the uptake and transmission of information by nonhuman animals (Brandom 2000, pp. 2-3).

The linguistic and rationalist version of fundamental pragmatism is certainly a substantial philosophical position, not vulnerable to trivialization. It will be roundly countered not only by those who think that Brandom overemphasize the discontinuity between information processing by animals and human discursive practices, but also by those who believe, like Stanley and Williamson (2001), that knowledge how is simply knowledge that in disguise. Moreover, one may also argue that in the domain of linguistic practices it is impossible to draw a clear distinction between knowledge that and knowledge how, and thus any attempt to ground the former in the latter is doomed to failure from the start. ${ }^{5}$ Whether Brandom is able to respond to these challenges and successfully defends the primacy of the practical, and hence to show that knowing how has a certain kind of priority over knowing that, seems to depend, to a large extent, on the viability of the view within the philosophy of language which supports this priority. Such a view will be a local pragmatism. Brandom calls it semantic pragmatism and insists that it "enforces a restriction on the vocabulary a semantic pragmatist can use to describe the linguistic practices that establish the association of semantic interpretants with linguistic expressions" (2002a, p. 47). The restriction is that the vocabulary cannot be exclusively intentional. The question of crucial importance is whether there is a defensible version of such a view.

\section{Semantic Pragmatism}

Let us notice first that the term "semantic pragmatism" is to a certain extent misleading. The reason is that the view labeled by this term does not especially prize semantics, does not assign it the central role in an account of language, but rather emphasizes that it should be answerable and subordinate to pragmatics. That is to say, semantic pragmatism insists on the priority of pragmatics (a study of the ways linguistic expressions are used) over semantics (a study of the sense and reference of linguistic expressions). As Brandom puts it:

While the meanings studied by semantics may not consist in the roles played by expressions in linguistic practice (meaning need not be identified with use),

\footnotetext{
${ }^{5}$ This is the line taken by Michael Dummett (see e.g. his 1993, p. 160).
} 
according to this view those roles must at least establish the connection between contents, meanings or semantic interpretants, on the one hand, and linguistic expressions on the other. The semantic pragmatist's basic insight is that there is nothing apart from the use of expressions that could establish such connections (2002a, p. 45).

There are at least two claims involved here. Although Brandom does not assume that meaning is just use, he insists that use has explanatory priority over meaning or content. That is, it is use of expressions which determines what meanings, if any, they have. Furthermore, use of expressions may be conceived in broadly functionalist terms: as the roles played by expressions in a wider linguistic practice or game.

The first thing to notice is that the explanatory priority may be understood here in may ways. Following John MacFarlane (2010) at least two of them should be clearly distinguished. One is a rather weak requirement which may be put like this: meanings are assigned to expressions in virtue of their use. Thus it is use which explain why a given expression has a certain meaning, and not the other way round. This leads to the following claim about the relationship between semantics and pragmatics: "Semantics is not conceptually autonomous from pragmatics; semantic concepts get their significance through their relation to pragmatic concepts" (MacFarlane 2010, p. 88). Brandom often encapsulates this dependence in the slogan: semantics must be answerable to pragmatics. As it stands the slogan seems incontrovertible, but it does not have any substantial consequences. One can happily accept it, and still face a choice between an inferentialist account of meaning and a truth-conditional one, as well as between a rationalist version of fundamental pragmatism and any other version of it or, perhaps, any other philosophical view. Thus, as MacFarlane rightly points out, Brandom needs for his purposes much stronger reading of the explanatory priority.

This much stronger reading requires a complete account of meaning in terms of use. Hence perhaps the best way of expressing the core idea of semantic pragmatism is not by way of a vague requirement that semantics must to answerable to pragmatics, but by insisting that "the fundamental semantic concepts can be defined in purely pragmatic terms" (MacFarlane 2010, p. 89). Semantic pragmatism under such construal is certainly a substantial doctrine and a useful tool for elimination of semantic theories which Brandom finds unacceptable. However, its feasibility depends on what those "purely pragmatic terms" are, and especially, how use of expressions may be specified and described.

There seems to be two major options here. First, use may be specified in explicitly semantic terms. For instance, one may describe the use of a given expression by saying that it enables one to refer to a certain item or to express a certain content. This way of proceeding will surely identify and fully describe the meaning of the expression, as well as ensure its definition in terms of use. However, it will achieve this aim at the price of triviality and lack of any explanatory power whatsoever. It will also make semantic pragmatism an empty doctrine. Brandom himself notices this disastrous consequence as he writes: "If one is allowed to use the full resources of semantic vocabulary in specifying the use-describing an operator as 'used so as to express negation', or a term as 'used to refer to Leibniz', then the 
requirements of semantic pragmatism will automatically be met” (2002a, p. 45). He also repeats this point in his John Locke Lectures:

The semantic pragmatist's claim that use confers meaning (so talk of practices or the exercise of abilities as deploying vocabularies) reverts to triviality if we are allowed to talk about "using the tilde to express negation," "the ability to mean red by the word 'red'," or "the capacity to refer to electrons by the word 'electron'," (or, I think, even intentions so to refer) (Brandom 2008, p. 9).

Thus if one wants to have semantic pragmatism as an interesting and substantial view, one should avoid describing the use of expressions in explicitly semantic terms.

The failure of the first way of specifying use, suggests a radically different approach. One may attempt to grasp and express all intricacies of language use in non-semantic terms, that is, without invoking the notion of meaning or content in identifying, differentiating, and describing varieties of linguistic use. To achieve this one would have to describe use mainly in physical and biological terms. The psychological expressions would be allowed only if they are taken to refer to "psychological states construed in non-representational or non-conceptual termsbehavioural (or more broadly, functional) dispositions of various kinds" (Price 2004, p. 197). If such an austere functionalist description of linguistic use succeeds, one would have all required resources to provide a non-circular and non-trivial account of meaning or content, along the lines recommended by Brandom. Yet it is doubtful whether such a functionalism is an available option for him. Of course, one may be inclined to read in this sprit Brandom's statement that pragmatism as adopted by him

seeks to explain what is asserted by appeal to features of assertings, what is claimed in terms of claimings, what is judged by judgings, and what is believed by the role of believings (indeed, what is expressed by expressings of it) - in general, the content by the act, rather than the other way around (Brandom 2000, p. 4).

Nevertheless this strategy does not warrant by itself that the act that explains a given content, for instance the act of asserting that is supposed to explain what is asserted, can be specified in austerely behavioural or functional terms, independently of and without appealing to what is asserted. It is sometimes argued that even if it does not provide such a warrant, then at least it does not start with "states already thought of as possessing content"; instead it begins with "something more basic" (Price 2004, p. 197). It seems to me, however, that this is not the best way of putting the matter. For instance, asserting something is rather in no interesting sense more basic than what is asserted; it is presumably a more encompassing and situated phenomenon than the content of assertion, and thus bringing it into play may be useful in specifying and explicating of the content in question. But it is one thing to notice that and insist, as Brandom does, that in explaining meaning or content we cannot confine ourselves to employing "exclusively intentional vocabulary" (2002a, p. 47), and quite another one to endeavor to reduce content to something more basic.

Moreover, Brandom constantly emphasizes that our practice is permeated with normativity. That is to say, almost everything we do is governed by rules or norms. Things we do can be done either correctly or incorrectly, either in consonance with appropriate rules or in conflict with them. And this indispensable and ubiquitous normativity cannot be reduced, Brandom claims, to mere regularity of behaviour, or 
anything else, for that matter. This is especially true about our discursive and linguistic practice of giving and asking for reasons, which is, in accordance with rationalist pragmatism, the center of our activities. Thus pragmatics to which semantics is answerable has to be essentially normative. It cannot restrict its vocabulary to purely descriptive terms and provide us with an account of our linguistic practice as an activity of making various noises in certain circumstances. Any restriction of this kind, Brandom insists, "renders invisible the very phenomena we discuss under such rubrics as 'meaning', 'understanding', 'assertion', 'belief' and 'intention'” (2002a, p. 49). However, if pragmatics which is supposed to explain semantic properties of our linguistic expressions cannot be confined, even at the most basic level, to an account of our linguistic practice in terms of various noises we make, but rather from the very beginning has to construe those noises as claims or assertions that are in given circumstances appropriately or inappropriately, correctly or incorrectly, made, then one seems to specify and describe them from the very beginning in terms of their semantic properties. If this is indeed so, then presumably there is no interesting and non-trivial sense in which normative pragmatics is able to explain semantics.

Brandom is well aware that normativity poses a challenge for his project of semantic pragmatism. However, he formulates this challenge in terms of the alleged incompatibility of normative pragmatics with naturalism. And he assures his readers that this challenge can be met. That is to say, in describing our linguistic practice one may "distinguish performances that are correct in various senses from those that are not" and "talk of what one commits oneself to or becomes responsible for by producing a speech act", without depriving oneself of the prospect of "an ultimately naturalistic account of the applicability of such normative assessments" (Brandom 2002a, p. 50). Maybe Brandom is right in his assurance, and normativity can indeed be fully explained in a naturalistic framework. But it is one thing to provide such an explanation, and quite another one to give an account of our linguistic performances and their correctness in non-semantic terms. In other words, one may hold that there is nothing in our speech acts which eludes description and explanation in broadly naturalistic terms, that is, in terms of physical, biological, and social sciences, but insists that in describing them as assertions, questions, promises, etc., or, in Brandom's preferred normative vocabulary, as commitments we make, to which we are entitled, and for which we are responsible, one has to use explicitly semantic terms, and right from the start talk about their content or significance.

In his more programmatic and dramatic moments Brandom suggests that sooner or later one has to face a choice between semantic pragmatism and semantic platonism. The former "seeks to explain how the use of linguistic expressions, or the functional role of intentional states, confers conceptual content on them" (Brandom 2000, p. 4). The latter reverses this explanatory strategy: it first assigns meaning or content to linguistic expressions, and subsequently tries to explain "how associating such content with sentences and beliefs contributes to our understanding of how it is proper to use sentences in making claims, and to deploy beliefs in reasoning and guiding action" (Brandom 2000, p. 4). ${ }^{6}$ This choice seems

\footnotetext{
${ }^{6}$ MacFarlane (2010, p. 94) correctly notices that the term "semantic platonism" is a rather misleading in this context, since among proponents of the anti-pragmatist position denoted by it are Fred Dretske and Jerry A. Fodor whose views have nothing to do with platonism, even in a very loose sense.
} 
to reflect the more general opposition drawn by John Dewey: between pragmatism and platonism (or intellectualism). For Brandom this opposition amounts to different orders of explanation: "pragmatists appeal to knowing-how in order to explain knowing-that (or, more carefully, saying- or believing-that), and their intellectualist opponents (virtually the entire prior philosophical tradition, they thought) go the other way around, finding principles standing behind every propriety of practice, and rules grounding every practical ability" (2008, p. 40). Unfortunately, this way of arguing for semantic pragmatism refers back to fundamental pragmatism, which in its rationalist version endorsed by Brandom, requires a significant support from detailed doctrines in the philosophy of language and mind, and not the other way round.

\section{The Dilemma and Evasion}

Brandom makes clear a number of times that he does not want to be forced to make a choice between a weak version of semantic pragmatism, formulated in terms of answerability to pragmatics, and a strong one, requiring definability of semantic categories in pragmatic terms, or reducibility of the former to the latter. He also does not want to choose between austere functionalist and physicalist specification of use, and a rich account of it in normative semantic and pragmatic terms. His resistance in this matter reflects his conviction that "the proffered alternatives are not exhaustive" (Brandom 2010a, p. 314).

An impressive attempt to justify his conviction is contained in his Oxford John Locke Lectures (2008). He claims there right at the beginning that his primary aim is to defend a form of analytic pragmatism which situates "concern with the meanings of expressions in the broader context of concern with proprieties governing their use" (Brandom 2008, p. xii). However, it is not fully clear what this situating amounts to. The initial idea is simple and fruitful. We begin with a given vocabulary and try to identify some set of practices and abilities sufficient to make a competent use of it and thus determine meanings of its expressions. Of course, these practices and abilities need to be somehow specified in another vocabulary, which is for a given target vocabulary its metavocabulary. In this way one obtains an interesting relationship between two vocabularies. The relationship is semantic but pragmatically mediated one. It is especially pertinent to the project of semantic pragmatism that in many cases pragmatic metavocabularies differ in their expressive powers from corresponding vocabularies to which they are related. Brandom calls this phenomenon "pragmatic expressive bootstrapping", and notices that there are cases in which a metavocabulary is considerably weaker than its corresponding target vocabulary (it is the phenomenon of strict expressive bootstrapping). He writes:

We are familiar with this sort of phenomenon in ordinary semantics, where sometimes a semantic metalanguage differs substantially in expressive power from its object language-for instance, where we can produce an extensional metalanguage for intensional languages, as in the case of possible worlds semantics for modality (Brandom 2008, p. 11). 
Another more controversial example, devised by Brandom himself, is pragmatically mediated vocabulary for indexical vocabulary. One has here a clear case of strict expressive bootstrapping, since "in spite of the semantic irreducibility of indexical to non-indexical vocabulary, it is possible to say, entirely in non-indexical terms, what one must $d o$ in order to be deploying indexical vocabulary correctly" (Brandom 2008, p. 25). ${ }^{7}$

Nevertheless even if the phenomena of strict expressive bootstrapping were extremely common and unquestionable (which is rather unlikely), they would merely support the idea of mutual interdependence between semantics and pragmatics, that is, their unavoidable entanglement. But it seems that in order to realize his ambitious philosophical project Brandom very often needs something more, namely the explanatory priority of pragmatics over semantics in a strong sense. And this requirement will force him, sooner or later, into a rather uncomfortable position of use specification in terms of austerely functionalist terms, and construction of semantic categories out of this meager material.

\section{Conclusion}

It is often claimed that Brandom is a systematic philosopher whose views form a tight theoretical package of mutually connected conceptions. But even in such a package some conceptions must be more basic than others, some views must underpin and support other views, and not the other way round (dependence and interdependence in this respect cannot be perfectly symmetrical on pain of circularity). I have tried to show that for Brandom his local semantic pragmatism is of more justificatory relevance than his global and programmatic fundamental pragmatism. The latter appears to be either trivial or loaded with questionable philosophical assumptions, which requires further support. It seems that some support might be provided by his semantic pragmatism. However, this particular view faces the dilemma of being an unhelpful platitudinous doctrine or theoretically fruitful but implausible conception requiring the reducibility of semantic categories to narrowly conceived pragmatic ones. Brandom has recently made an attempt to evade this dilemma by invoking the idea of pragmatic expressive bootstrapping, but the attempt is not fully convincing. ${ }^{8}$

\footnotetext{
${ }^{7}$ As John McDowell suggests (2008) it is much harder to accomplish this feat than Brandom thinks. When we describe what one must do to be deploying indexical vocabulary, we can refrain from making explicit use of it, but we cannot avoid presupposing it in a more or less implicit way.

${ }^{8}$ A former version of this paper was presented at the workshop on Robert B. Brandom's Philosophy of Language, "Towards an Analytic Pragmatism", University of Genoa, April 2009. I am indebted to Professor Brandom and participants of the workshop for useful comments and stimulating discussion. The financial support of the Polish Ministry of Science and Higher Education is also gratefully acknowledged (individual research project no. N N101 317234). The final version of the paper was prepared while I was a fellow-in-residence at the Netherlands Institute for Advanced Studies in the Humanities and Social Sciences. I gladly acknowledge the hospitality of this institution and extremely helpful comments from an anonymous referee which guided me though the process of revision.
} 
Open Access This article is distributed under the terms of the Creative Commons Attribution Noncommercial License which permits any noncommercial use, distribution, and reproduction in any medium, provided the original author(s) and source are credited.

\section{References}

Baghramian, M. (2008). Three pragmatisms: Putnam, Rorty, and Brandom. In M. U. R. Monroy, C. C. Silva, \& C. M. Vidal (Eds.), Following Putnam's trail: On realism and other issues (pp. 83-101). Amsterdam: Rodopi.

Brandom, R. B. (2000). Articulating reasons: An introduction to inferentialism. Cambridge: Harvard University Press.

Brandom, R. B. (2002a). Pragmatics and pragmatisms. In J. Conant \& U. M. Żegleń (Eds.), Hilary Putnam: Pragmatism and realism (pp. 40-58). London: Routledge.

Brandom, R. B. (2002b). Tales of the mighty dead: Historical essays in the metaphysics of intentionality. Cambridge: Harvard University Press.

Brandom, R. B. (2004). The pragmatist enlightenment (and its problematic semantics). European Journal of Philosophy, 12, 1-16.

Brandom, R. B. (2008). Between saying and doing: Towards an analytic pragmatism. Oxford: Oxford University Press.

Brandom, R. B. (2009). Reason in philosophy: Animating ideas. Cambridge: Harvard University Press.

Brandom, R. B. (2010a). Brandom's responses. In B. Weiss \& J. Wanderer (Eds.), Reading Brandom: On "Making it explicit” (pp. 295-365). London: Routledge.

Brandom, R. B. (2010b). Perspectives on pragmatism: Classical, recent, and contemporary. Cambridge: Harvard University Press. forthcoming.

Dummett, M. (1993). Origins of analytical philosophy. London: Duckworth.

Malachowski, A. (2010). The new pragmatism. Acumen: Durham.

MacFarlane, J. (2010). Pragmatism and inferentialism. In B. Weiss \& J. Wanderer (Eds.), Reading Brandom: On "Making it explicit" (pp. 81-95). London: Routledge.

McDowell, J. (2008). Comment on lecture one. Philosophical Topics, 36(2), 45-53.

Misak, C. (Ed.). (2007). New pragmatists. Oxford: Clarendon.

Price, H. (2004). Immodesty without mirrors: Making sense of Wittgenstein's linguistic pluralism. In M. Kölbel \& B. Weiss (Eds.), Wittgenstein's lasting significance (pp. 179-205). London: Routledge.

Putnam, H. (2002). Comment on Robert Brandom's paper. In J. Conant \& U. M. Żegleń (Eds.), Hilary Putnam: Pragmatism and realism (pp. 59-65). London: Routledge.

Stanley, J., \& Williamson, T. (2001). Knowing how. The Journal of Philosophy, 98, 411-444.

Taylor, C. (2004). What is pragmatism. In S. Benhabib \& N. Fraser (Eds.), Pragmatism, critique, judgment: Essays for Richard J. Bernstein (pp. 73-92). Cambridge: The MIT Press. 